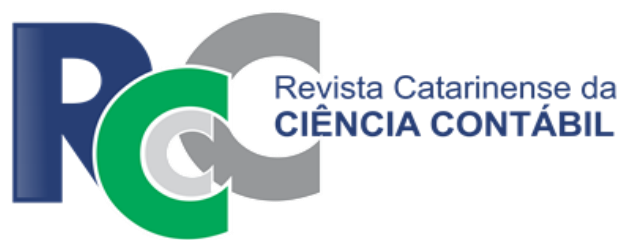

\title{
SIMULADOR DE CUSTOS PARA GESTÃO DE RISCOS DE ACIDENTES DE TRABALHO
}

\section{COST SIMULATOR FOR RISK MANAGEMENT OF WORK ACCIDENTS}

\author{
MARINO LUIZ EYERKAUFER \\ Universidade do Estado de Santa Catarina. Endereço: Rua Dr. Getúlio \\ Vargas, $2822 \mid$ Bela Vista | Ibirama/SC | Brasil. \\ (D) http://orcid.org/0000-0001-6038-1704 \\ marino.luiz@udesc.br
}

ERNANI AUGUSTO BONFANTE

Universidade do Estado de Santa Catarina. Endereço: Rua Dr. Getúlio Vargas, 2822 | Bela Vista | Ibirama/SC | Brasil. (1) http://orcid.org/0000-0001-5906-8657

ernani_bonfante@hotmail.com

\section{LARA FABIANA DALLABONA}

Universidade do Estado de Santa Catarina. Endereço: Rua Dr. Getúlio Vargas, $2822 \mid$ Bela Vista | Ibirama/SC | Brasil.

(1) http://orcid.org/0000-0002-7158-247X

lara.dallabona@udesc.br

\section{VALKYRIE VIEIRA FABRE}

Universidade do Estado de Santa Catarina. Endereço: Rua Dr. Getúlio Vargas, 2822 | Bela Vista | Ibirama/SC | Brasil.

(D) http://orcid.org/0000-0002-4664-1415

valkyrie.fabre@udesc.br

\begin{abstract}
RESUMO
Os acidentes de trabalho são recorrentes desde os primórdios. No Brasil, apesar de órgãos reguladores e empresas terem se esforçado em ampliar a segurança nas últimas décadas, as estatísticas são alarmantes e as consequências atingem empresas, funcionários e familiares, além de afetar a economia da nação, atingindo toda a sociedade. A literatura parece unânime quanto aos benefícios da aplicação de recursos em segurança, mas observa-se uma lacuna em relação à composição desses custos - em quê e quanto aplicar -, além da mensuração financeira. Assim, o estudo objetiva desenvolver ferramenta de simulação de custos para gestão de risco de acidentes de trabalho. Trata-se de pesquisa descritiva, qualitativa e que apresenta um modelo inédito na literatura, que traz contribuições singulares à gestão de risco de acidente de trabalho, com base na metodologia de gerenciamento de riscos e desastres adotada pela Proteção e Defesa Civil no Brasil e no mundo, compreendendo as fases antes, durante e depois dos desastres. Utilizam-se elementos de custos, com proposta de nova classificação a ser empregada na gestão de riscos de acidente de trabalho. Culmina em um simulador de custos que permite ao gestor equilibrar suas finanças em cada fase do ciclo de gestão proposto. O modelo foi validado em estudo de caso real, concluindose que os custos das fases de prevenção, mitigação e preparação são melhores que os de resposta e recuperação, pois trata-se de dor e vida poupadas, além de recursos financeiros. O modelo permite generalização, já que os elementos de custos podem ser adaptados a diferentes ramos de
\end{abstract}


atividade. A proposta é utilizar a nova classificação dos custos para gerenciamento dos riscos de acidente de trabalho, com base no simulador modelo apresentado.

Palavras-chave: Gerenciamento de riscos. Riscos de trabalho. Gestão de custos. Acidentes de trabalho. Simulador de custos.

\begin{abstract}
Occupational accidents have recurred since the beginning. Although there has been an effort by regulators and companies to increase safety in the last decades, statistics are alarming and the consequences affect companies, employees and their families, as well as the nation's economy, impacting the whole society. Literature seems unanimous on the benefits of applying security resources, but there is a gap in the composition of these costs - where and how much to applyin addition to financial measurement. In this sense, the objective of this study is to develop a cost simulation tool to manage occupational accidents risks. It is a descriptive, qualitative research that presents an unprecedented instrument in literature, which brings in its essence singular contributions to the management of work-related accident risk. The model is part of an adaptation of the methodology used to manage risks and disasters, adopted by Civil Protection and Defense in Brazil and in the world, which comprise the stages before, during and after disasters. Cost elements are used, proposing a new classification to be employed in the risk management of work accidents. It culminates in a cost simulator, which allows the manager to balance his finances at each stage of the proposed management cycle. The model was validated in a real case study. It was concluded that the costs of the prevention, mitigation and preparation phases are better than the costs of response and recovery, since it is pain and lives that are spared, as well as financial resources. The model allows generalization, since the cost elements can be adapted to the branch of activity of each company. The proposal is to use the new cost classification to manage occupational accident risks.
\end{abstract}

Keywords: Risk management. Occupational risks. Cost management. Accidents at work. Cost Simulator.

\title{
1 INTRODUÇÃO
}

A mudança no atual ambiente de negócios das organizações decorre da maior competitividade e globalização, fatores que levam as empresas a rever suas políticas e estratégias para adaptar-se ao ambiente com vistas a melhorar seu desempenho e permanecerem no mercado (Parente, Luca \& Vasconcellos, 2015). Nesse ambiente competitivo das empresas, muitos gestores não dão suficiente atenção ao ambiente laboral e, com isso, não percebem os danos a que expõem seus funcionários (Araújo, Santos \& Mafra, 2006).

A segurança, por sua vez, é uma variável inversamente proporcional ao risco, pois quanto maior o risco, menor a segurança (e vice-versa), ao aumentar a segurança torna-se possível reduzir os riscos. Por isso toda atividade precisa ser realizada com garantia de segurança, conforme normas/recursos necessários para executar determinada função, seja ela de uso pessoal ou coletivo, uma vez que é importante utilizar corretamente os equipamentos na realização dos trabalhos (Ferreira, Souza, Ribeiro, Galdino \& Ricci, 2012).

Segundo Revista Proteção (2016), as estatísticas do Anuário Brasileiro de Proteção de 2015, sobre sinistros - especificamente acidentes de trabalho - apontam que, após um período de sucessivas quedas nas médias históricas, que atingiram $-57,94 \%$ nos anos 90 , passaram a apresentar evolução significativa nos últimos anos - média de $+8,95 \%$ nos anos 2000 e $+39,67 \%$ no quadriênio 2010-2013 -. Estudos como o de Iwamoto, Camargo, Tavares e Miranzi (2011), Soares (2012) e Maia (2015), apontam para a crescente subnotificação desses sinistros.

Segundo Ferreira et al. (2012), além dos trabalhadores, a segurança no trabalho interessa também às empresas e à sociedade, pois, além de sofrimentos pessoais, o trabalhador acidentado 
ocasiona despesas ao sistema previdenciário, que passa a pagar benefícios, custeados por trabalhadores e empresas. Há de se frisar que acidentes de trabalho figuram como um sério problema de saúde pública, representando $4 \%$ do produto interno bruto mundial (Hämäläinem, Saarela \& Takala, 2009), e responsáveis por $18 \%$ dos óbitos nos países de média e baixa renda e $5 \%$ nos países de alta renda (Takala et al., 2014).

No Brasil, esses acidentes representam ainda um terço dos atendimentos por causas externas realizados nos serviços de saúde, gerando custos nas portas de entrada de urgência, internações, reabilitações e medicamentos (Ministério da Saúde, 2014). Além disso, gastos com afastamentos e aposentadorias somam mais de $60 \%$ dos benefícios pagos pela Previdência Social (Santana, Araújo, Albuquerque \& Barbosa, 2006) e representam um custo de R $\$ 71$ bilhões, o que equivale a quase $9 \%$ da folha salarial do país (Pastore, 2011).

Ainda com base em estatísticas oficiais, no período de 1988 a 2011 foram registradas mais de 80.000 mortes, ocorrendo ao menos 2.800 por ano, cuja maioria era resultante de acidentes e doenças consideradas evitáveis (Portal do Brasil, 2014). Acidentes geram custos, e por isso, a melhor maneira de minimizá-los nas empresas ainda é investir na prevenção dos acidentes de trabalho, sendo a prevenção e a antecipação ao fato o objetivo dos profissionais de segurança do trabalho (Ferreira et al., 2012).

Os acidentes e doenças do trabalho causam dor e sofrimento à vítima, seus familiares e companheiros de trabalho. Os custos desses acidentes oneram qualquer atividade produtiva. Entretanto, por meio de uma avaliação adequada dos custos dos acidentes, a gerência pode perceber que um programa de segurança adequado e eficiente representa mais que um gasto/despesa, e o quão favorável é a intervenção desse programa na produtividade (Franz, 2006).

Apesar de ter sido aplicado muito trabalho físico e mental na prevenção de acidentes, e grandes somas de recursos na criação de métodos e dispositivos, os acidentes continuam ocorrendo e desafiando os esforços, com muitas vidas perdidas, sendo as causas quase sempre atribuídas a fatores humanos (Ferreira et al., 2012).

$\mathrm{Na}$ literatura atual discute-se o gerenciamento dos riscos de modo corporativo. Várias entidades, como o The Risk Management (RMA), Risk and Insurance Management Society (RIMS), Casualty \& Actuarial Society (CAS), além do Committee of Sponsoring Organizations of the Treadway Commission (COSO), consideram que o conceito de gestão de risco merece ser ampliado para uma visão corporativa e não ser analisado de forma individualizada por tipo de risco e/ou área da empresa. Todos os tipos de riscos presentes precisam compor um gerenciamento eficiente, e nesse contex to surge a expressão "gestão de risco corporativo", conhecido na literatura também como Enterprise Risk Management (ERM) (Ching, 2011).

A nomenclatura dos custos gerados pelos acidentes ocorridos, ou pelo risco deles ocorrerem, é um tanto diversa. Benite (2004) e Franz (2006) abordam-nos como "custos de prevenção" (ou "custos da segurança") e "custos do acidente" ("custo da não segurança"). Lopes, Queiroz e Leonardi (2010) trazem ainda os conceitos de "custo segurado" e "custo não segurado". Os autores Liu, Hwang e Liu (2009) adotam os termos "segurado" e "não segurado" para referirse aos custos diretos e indiretos.

Já no modelo de gestão de riscos e desastres adotados pela Proteção e Defesa Civil, para o Centro Universitário de Estudos e Pesquisas Sobre Desastres [CEPED/UFSC], (2014), o gerenciamento de riscos compreende o processo da prevenção, mitigação, preparação, resposta e recuperação. Não foi possível identificar na literatura nacional, estudos na gestão de riscos do trabalho que abordem esse processo.

Diante do exposto, considerando a importância da gestão estratégica de custos no controle de riscos e a importância de consolidar uma metodologia para simular os custos nas diferentes fases do processo de gerenciamento, surge o objetivo da pesquisa: desenvolver uma ferramenta de simulação de custos para a gestão de riscos de acidentes de trabalho.

A justificativa da pesquisa vem ao encontro das questões expostas, relacionadas com o fardo gerado pelos acidentes de trabalho para as empresas. Os estudos identificados na literatura ainda não oferecem alternativas suficientemente elaboradas que permitam aos gestores definir sua 
política de gestão de riscos de trabalho. Bonfante, Eyerkaufer e Dallabona (2017) apontam dois aspectos relacionados à gestão de riscos em acidentes de trabalho que carecem de contribuições teóricas e práticas: as iniciativas além das compulsórias sobre segurança no trabalho; e o desenvolvimento de metodologias apropriadas de gerenciamento de riscos. Esta pesquisa tem foco no segundo aspecto levantado pelos autores.

A relevância do estudo não se restringe ao campo da gestão empresarial, pois trata-se de vidas que alavancam a economia do país. Para Fabre e Eyerkaufer (2018), a gestão de riscos exige políticas de junção e organização de esforços, que partem do ente público para integração dos demais setores da sociedade, em forma de pessoa física ou jurídica. Nesse sentido, é importante identificar os custos dos acidentes de trabalho para dar suporte técnico à novas políticas públicas, em benefício de trabalhadores e empresários, na promoção do bem-estar social.

\section{GESTÃO DE RISCOS}

A gestão de riscos envolve atividades de controle de gestão estruturadas e controles internos (Dalvesco, Fernardes \& Roncon, 2014). Para International Association of Insurance Supervisors [IAIS], (2008), a gestão de riscos é um processo de identificação, mensuração, monitoramento, controle e mitigação dos riscos numa empresa. A premissa do gerenciamento de risco corporativo é de que as organizações existem para gerar valor às partes interessadas, porém enfrentam incertezas e o desafio dos administradores está em determinar até que ponto aceitar essas incertezas. Por meio do gerenciamento dos riscos corporativos, os administradores podem lidar de modo eficaz com incertezas, riscos e oportunidades (COSO, 2007).

Apesar de as pessoas costumeiramente atribuírem conotação negativa aos riscos por associá-los a eventos com efeitos negativos, como perdas resultantes de fatores internos e externos à organização, uma boa gestão dos riscos pode ter sentido positivo. Seus principais efeitos são sentidos internamente com um melhor funcionamento organizacional, devido à adequada gestão dos recursos das empresas e à prevenção de comportamentos inadequados (Tavares, Pacheco \& Pires, 2016).

Em se tratando da integração de políticas públicas com os demais setores da economia, Fabre e Eyerkaufer (2018) afirmam que a gestão de riscos é um instrumento que, de forma interinstitucional, permite eliminar ou reduzir fatores de risco, administrar eventos adversos quando eles ocorrem em um cenário vulnerável, e, ainda recuperar esse cenário. Afirmam ainda que a gestão de risco passa por uma mudança de paradigma no Brasil, onde a cultura da reação dá lugar a cultura da prevenção.

A prevenção, para Melo, Castro e Regis (2008), constitui um conjunto de ações com o propósito de evitar erros ou defeitos, incluindo a organização do trabalho e as relações sociais na empresa. Por conseguinte, a verdadeira prevenção integra-se ao trabalho e implica três ações fundamentais: planejar previamente as operações, elaborar os procedimentos corretos e preparar o programa de formação profissional. Por fim, os autores afirmam que, segundo pesquisas realizadas nessa área, análises de acidentes e doenças ocorridas no trabalho apontam como principal causa a deficiência na gestão da integração da prevenção de riscos, alinhada aos processos produtivos. Para Piza (2000), a prevenção é sinônimo de lucro e significa garantir que o processo produtivo transcorrerá em harmonia.

Bonfante et al. (2017) desenvolveram um modelo de gestão dos riscos de trabalho simplificado e de fácil atendimento e adoção para empresas, baseado nos acidentes que ocorrem possivelmente por não seguirem à risca a legislação sobre segurança do trabalho. Para isso, foi realizada uma pesquisa qualitativa em 15 empresas industriais que identificou as deficiências na gestão de riscos de trabalho. O modelo consiste basicamente em fazer um planejamento estratégico alinhado aos vários setores da empresa, como produção e segurança, em que todos se sentem valorizados, a partir do processo de monitoramento dos riscos laborais, desde a identificação até o tratamento dos riscos. Desse modo, objetiva-se reduzir os riscos e, por consequência os custos de um possível acidente de trabalho. 


\subsection{Custos no gerenciamento de riscos de acidentes de trabalho}

Conforme Silva e Mendonça (2012), nesse contexto de mundo globalizado é importante que as organizações não fiquem tão somente preocupadas com o desenvolvimento da produção e a comercialização dos seus produtos ou serviços. É importante que as empresas vejam seus colaboradores não apenas como meros recursos produtivos, mas que estejam preocupadas com os impactos de atividades para a saúde e a segurança do trabalhador, bem como para o mercado consumidor e toda sociedade. De acordo com Franz (2006), os custos são significativos para a sociedade, mas de difícil mensuração. Reforça Benite (2004) que, além dos custos financeiros, é preciso destacar e dar importância para as consequências provocadas nas famílias, como sofrimento e prejuízo na qualidade de vida.

A nomenclatura utilizada em pesquisas de contabilidade gerencial pode causar divergências de entendimento até na própria ciência contábil. Em pesquisas internacionais, o termo “cost” já está consolidado, como sinônimo dos gastos em geral. Porém, alguns autores no Brasil, como Martins (2010), definem os gastos como a soma dos custos, despesas e investimentos de uma empresa. Neste estudo, o conceito internacional de custos e a linguagem nacional de gastos serão utilizados como sinônimos, ambos para representar os recursos que a empresa utiliza no processo de gerenciamento dos riscos de acidentes de trabalho.

Franz (2006) afirma que o custo de prevenir está relacionado com os custos da qualidade, pois, ao buscar qualidade, obtém-se prevenção e vice-versa. Já os custos dos acidentes podem estar relacionados à falta da qualidade no ambiente de trabalho.

Os custos da prevenção ou da segurança, como denomina Franz (2006), estão relacionados com o tempo e recursos utilizados no planejamento da prevenção de acidentes e nos controles implementados em locais de trabalho, uma vez que é possível fazer com que seja prevenida a maioria dos acidentes de trabalho. Lima (2003) demonstrou pela análise de custos realizada na empresa Japan Industrial Safetyand Association que os investimentos em segurança são pagos pela redução dos acidentes, e pelos seguintes retornos: a) melhor eficiência e produtividade; b) maior motivação dos trabalhadores; c) menor absentismo; d) menor rotação de trabalhadores; e) melhor qualidade do trabalho; f) menor gasto com despesas médicas.

Já os custos dos acidentes de trabalho ou da não segurança estão relacionados ao acidente ocorrido, aos prejuízos econômicos e despesas que ele ocasiona, como custos de atendimento médico, perdas de máquinas, perdas de tempo, de motivação, queda na produtividade, entre outros (Franz, 2006).Todavia, Benite (2004), ressalta que conhecer os custos da não segurança e da segurança não é tarefa simples, pois as variáveis envolvidas são difusas e difíceis de dimensionar como por exemplo: quanto custa a morte de um funcionário?; em quanto um acidente prejudica as vendas de uma empresa?; qual o percentual da queda de produtividade resultante da redução da motivação da equipe que presenciou o acidente?

O custo da não segurança, conforme cita Franz (2006), deve ser divulgado aos empresários. Para Benite (2004), o volume de recursos desperdiçados toda vez que um acidente ocorre já serve como forte argumento para que se estimule o investimento em segurança. Os custos da não segurança, segundo Benite, possuem ligação com o tratamento da consequência enquanto o custo da segurança está associado ao tempo e ao recurso utilizado para planejar a prevenção.

Além dos conceitos de "custos de prevenção" (ou "custos da segurança") e "custos do acidente" (ou "custos da não segurança"), trazidos por Benite (2004), Franz (2006), Vianna e Santos (1976), bem como Lopes et al. (2010), trazem ainda o conceito de "custo segurado" e "custo não segurado". Já os autores Liu et al. (2009) adotam os termos "segurado" e "não segurado" para referir-se aos custos diretos e indiretos.

De acordo com Vianna e Santos (1976), o custo segurado corresponde ao Seguro de Acidente de Trabalho (SAT), pago pelo empregador ao Instituto Nacional de Seguridade Social (INSS), cuja contribuição é calculada da seguinte forma:1\% (um por cento) para a empresa cuja atividade apresente risco de acidente de trabalho considerado leve; $2 \%$ (dois por cento) se o risco de acidente do trabalho for considerado médio; e 3\% (três por cento) se o risco de acidente do 
trabalho for considerado grave.

Vianna e Santos (1976) complementam, alegando que o percentual é calculado na folha de pagamento e recolhido com as demais contribuições devidas ao INSS. O custo não segurado, por sua vez, segundo a Associação Brasileira de Normas Técnicas [ABNT] (2001), corresponde à totalidade das despesas não cobertas pelo SAT e de difícil computação como as resultantes da interrupção do trabalho, do afastamento do empregado, dos danos causados aos equipamentos, da perturbação do trabalho normal e das atividades assistenciais não seguradas.

Devido aos vários conceitos para tratar das mesmas variáveis e considerando que há divergência em algumas classificações de custos, a Tabela 1 apresenta síntese dos principais custos abordados na literatura, classificando como custos diretos os relacionados antes da ocorrência do acidente e como indiretos os que incorrem após o acidente.

Tabela 1

\section{Custos abordados na literatura}

\begin{tabular}{|c|c|c|c|}
\hline Custos Diretos & Autores & Custos Indiretos & Autores \\
\hline $\begin{array}{l}\text { 1. Manutenção de equipes de segurança do } \\
\text { trabalho }\end{array}$ & \multirow{3}{*}{$\begin{array}{l}\text { Benite } \\
(2004)\end{array}$} & 1. Despesas jurídicas & $\begin{array}{l}\text { ABNT } \\
(2001)\end{array}$ \\
\hline $\begin{array}{l}\text { 2. Tempo de desenvolvimento de projetos e } \\
\text { instalações de proteção coletiva }\end{array}$ & & $\begin{array}{l}\text { 2. Tempo de recrutamento e gasto com } \\
\text { treinamento para o novo colaborador }\end{array}$ & $\begin{array}{c}\text { ABNT } \\
(2001) ; \text { Franz } \\
(2006)\end{array}$ \\
\hline $\begin{array}{l}\text { 3. Tempo dos trabalhadores utilizados } \\
\text { durante as atividades de treinamentos }\end{array}$ & & \multirow{2}{*}{$\begin{array}{l}\text { 3. Custo do atendimento médico, } \\
\text { medicamentos e reabilitação ao trabalho } \\
\text { 4. Pagamentos dos } 15 \text { dias de } \\
\text { afastamentos e indenizações }\end{array}$} & \multirow[t]{2}{*}{ Franz (2006) } \\
\hline 4. Manutenção da infraestrutura & \multirow{4}{*}{$\begin{array}{l}\text { Benite } \\
(2004) \text {; } \\
\text { Franz } \\
(2006)\end{array}$} & & \\
\hline 5. Custos com exames médicos/PCMSO & & $\begin{array}{l}\text { 5. Perdas e custos de danos de máquinas } \\
\text { e equipamentos }\end{array}$ & ABNT \\
\hline 6. Aquisição de EPI & & $\begin{array}{l}\text { 6. Perda de tempo de trabalho do } \\
\text { acidentado e dos companheiros de } \\
\text { trabalho }\end{array}$ & $\begin{array}{l}\text { (2001); Franz } \\
\text { (2006); } \\
\text { Lopes et al. }\end{array}$ \\
\hline $\begin{array}{l}\text { 7. Placas de identificação e orientação aos } \\
\text { trabalhadores }\end{array}$ & & $\begin{array}{l}\text { 7. Perda de motivação e queda na } \\
\text { produtividade }\end{array}$ & (2010); \\
\hline 8. Programa PPRA & $\begin{array}{l}\text { Franz } \\
(2006)\end{array}$ & $\begin{array}{l}\text { 8. Aumento de custo para o empregador } \\
\text { com relação à Previdência Social e } \\
\text { outras instituições que asseguram } \\
\text { benefícios aos trabalhadores }\end{array}$ & \\
\hline \multirow[b]{2}{*}{ 9. Custo relacionado ao seguro SAT } & \multirow{2}{*}{$\begin{array}{l}\text { Lopes et } \\
\text { al. } \\
(2010)\end{array}$} & $\begin{array}{l}\text { 9. Custo adicional devido à interrupção } \\
\text { da produção, gerado por dificuldade de } \\
\text { cumprir as atividades no tempo } \\
\text { requerido, multas por atraso, perda de } \\
\text { bonificações por atendimento de prazo, } \\
\text { pagamento de horas extras, entre outros } \\
\text { 10. Custos de acidentes subsequentes, } \\
\text { em consequência da agitação ou } \\
\text { fraqueza moral - estado emocional - dos } \\
\text { demais empregados devido à ocorrência } \\
\text { do acidente inicial }\end{array}$ & $\begin{array}{l}\text { ABNT } \\
(2001) \\
\text { Lopes et al. } \\
\text { (2010); }\end{array}$ \\
\hline & & $\begin{array}{l}\text { 11. Custo ao empregador do pagamento } \\
\text { integral do salário ao acidentado quando } \\
\text { de seu retorno, mesmo que o serviço } \\
\text { realizado por esse empregado - que } \\
\text { ainda não está plenamente recuperado - } \\
\text { tenha por algum tempo valor inferior } \\
\text { que o seu valor normal } \\
\text { 12. Custos indiretos por acidentado, } \\
\text { como iluminação, aluguel e outros itens } \\
\text { que continuam para empresa, mesmo } \\
\text { enquanto o acidentado ainda está } \\
\text { ausente e não produz }\end{array}$ & $\begin{array}{l}\text { Lopes et al. } \\
\qquad(2010)\end{array}$ \\
\hline
\end{tabular}

Fonte: elaborada pelos autores (2018). 
Ramos, Arezes e Afonso (2014) especificam ainda que para o empregador incorrem custos de pagamentos na ausência do trabalhador, prêmios de seguro, custos da perda de produção, custos administrativos e legais. Para o empregado, os custos são salários perdidos, custos de compensação, saúde, custos de reabilitação, entre outros. Finalmente, os custos para a sociedade são aqueles não suportados por empregadores ou empregados e incluem a redução de impostos, pagamentos de benefícios, reabilitação de tratamento médico, atividades administrativas e legais relacionadas.

Conforme Lopes et al. (2010), empresas são organizações dinâmicas em que setores ou departamentos atuam/interagem de forma estratégica, procurando atingir objetivos específicos como lucro, crescimento e permanência no mercado. Segundo Santana et al. (2006), em países que avançam no campo da prevenção, os custos dos acidentes de trabalho raramente são contabilizados. Afirmam ainda que acidentes correspondem de $4 \%$ a $10 \%$ do produto interno bruto (PIB), tendo em países em desenvolvimento índices mais elevados.

Enquanto alguns custos são de fácil percepção, outros não são identificados na totalidade, o que torna difícil sua mensuração (Lopes et al. 2010). Assim, afirmam ainda que programas de minimização de riscos procuram diminuir a ocorrência e a gravidade dos acidentes de trabalho, ao mesmo tempo em que contribuem para reduzir os custos da empresa, haja vista que a incidência de um acidente envolve várias perdas para empresa e trabalhador.

O Brasil em 2015 gastou 10 bilhões de reais anuais com indenizações e tratamentos com acidentes de trabalho. Entre os fatores de contribuição os autores destacam a alta rotatividade de mão de obra, existência de máquinas inadequadas e obsoletas e o excesso de jornada. Afirmam, ainda, que por restrições, cortes orçamentários e sucateamento de órgãos como o Ministério do Trabalho e Emprego e o Ministério Público do Trabalho, ocorre diminuição na físcalização do cumprimento das normas de proteção.

Pastore (2011) afirma que em 2009 a Previdência gastou 14 bilhões de reais com benefícios acidentários e aposentadorias especiais, e que as empresas incorrem em outros 41 bilhões, totalizando 55 bilhões de reais. Contudo, o autor considera elevar essa relação para 1:6 e chega a um gasto total de empresas e governo de 71 bilhões de reais, que representou $9 \%$ do total da folha salarial do país, um número significativo. Além disso, Pastore (2011) afirma tratar-se de um custo subestimado, já que leva em conta apenas os trabalhadores do mercado formal. Conforme o autor, o SUS atende muitos acidentados e adoecidos do mercado informal cujas despesas são pagas por outro órgão, o Ministério da Saúde e não pela Previdência.

Os empregadores não compensam totalmente seus empregados pelos custos de saúde relacionados ao trabalho. Parte das despesas médicas e dos salários perdidos são cobertos pelas companhias de seguros e pelos sistemas de seguro social. Contudo, os custos relacionados à perda da qualidade de vida são suportados pelos trabalhadores e seus familiares e precisam ser levados em conta (Ramos et al., 2014).

Segundo Ramos et al. (2014), cabe ao Estado e à sociedade cobrir as despesas com hospitalizações, tratamento, recuperação, pagamento de benefícios sociais aos lesionados, assim como custos associados a reintegração desses empregados no mercado de trabalho. Há que se levar em conta também as implicações na produtividade e na competividade na economia. Os autores procuraram responder às seguintes perguntas: quanto investir em saúde e segurança no trabalho? quanto gastar em medidas preventivas? quando cada investimento precisa ser feito?

\subsection{Processo de gerenciamento de riscos e desastres adotados no Brasil}

$\mathrm{Na}$ literatura têm surgido algumas metodologias para o gerenciamento de riscos como o COSO (2007), o PMBOK (2004) - esse voltado para o gerenciamento de riscos em projetos - ou a ISO 31000 - Gestão de Risco. No dia a dia das empresas também têm aparecido instrumentos para auxiliar no controle de riscos, como Mapa de Riscos ou a Análise Preliminar de Riscos (APR). Notam-se esforços dos autores em levantar, estimar e comparar os custos nas empresas analisadas, classificando-os em "diretos e indiretos", "custos de acidentes e custos de prevenção", "custo 
segurado e custo não segurado". Mas não se encontra uma relação entre o gerenciamento dos riscos envolvidos e os custos gerados pelo acidente evitado ou reparado.

Assim, o estudo buscou subsídio na metodologia adotada pela Proteção e Defesa Civil no Brasil e no mundo, a qual adota um processo de gerenciamento em que, de acordo com o CEPED/UFSC (2014), na Defesa Civil, as ações relacionadas aos desastres e os riscos compreendem as fases que ocorrem antes dos desastres, no caso a própria gestão dos riscos (prevenção, mitigação e preparação); durante (resposta) e depois (recuperação), esses últimos dois referem-se à gestão do desastre conforme Figura 1.

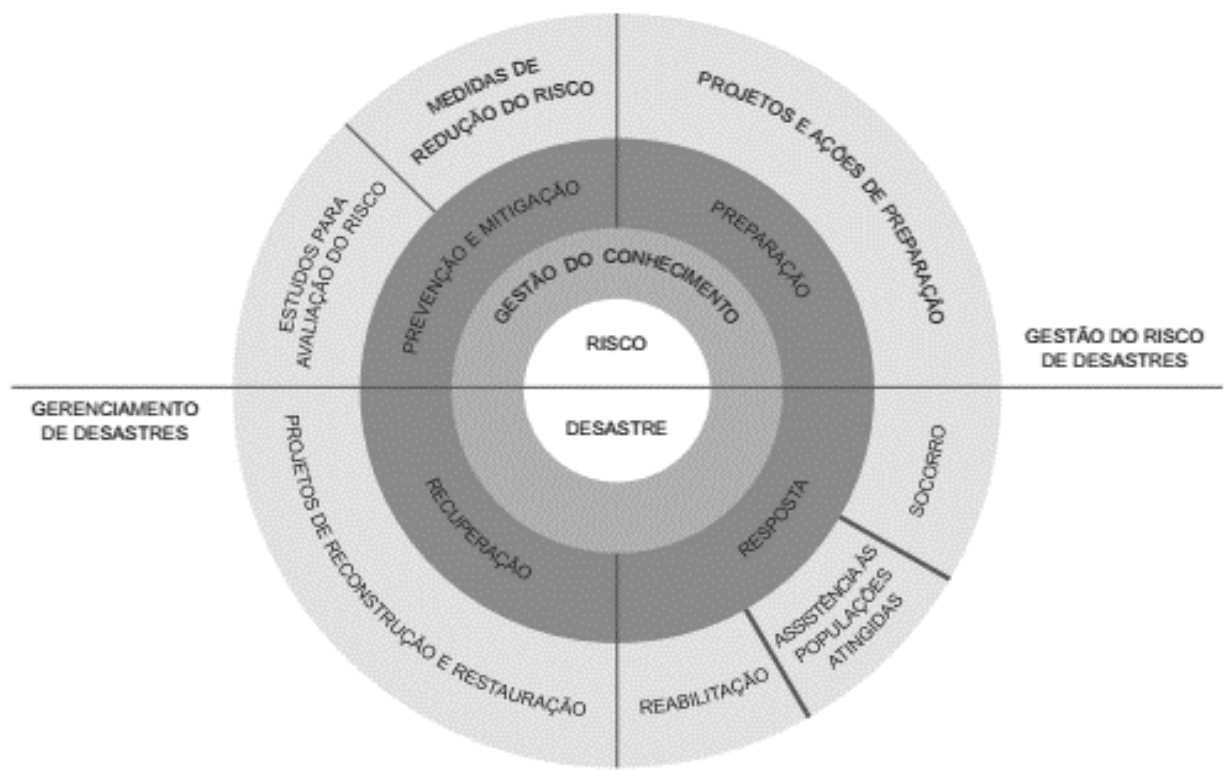

Figura 1. Ciclo de Gestão de Proteção e Defesa Civil Fonte: adaptada de Ferreira et al. (2012, p. 52).

Para o CEPED/UFSC (2014), a prevenção representa o conjunto de medidas adotadas com antecedência para evitar a instalação de situações de risco e, caso se instalem, que se convertam em desastres. Já a mitigação é o conjunto de medidas destinadas a diminuir ou limitar a configuração de situação de risco. Medidas mitigatórias buscam reduzir as consequências do evento, caso se materialize.

Eyerkaufer (2017) afirma que a mitigação deve ser alvo de estratégias na gestão dos riscos e desastres, uma vez que atua na minimização dos efeitos danosos gerados pelos eventos adversos que muitas vezes não podem ser prevenidos. A preparação diz respeito ao esforço interinstitucional para prever, responder e recuperar os impactos dos eventos adversos ou das condições prováveis, iminentes ou atuais que se relacionam com as ameaças (United Nations International Strategy for Disaster Reduction [UNISRD], 2009).

Corrobora Office of U. S. Foreign Disaster Assistance [OFDA] (2011) que a resposta corresponde às ações executadas, frente a um evento adverso, com objetivo de salvar vidas, reduzir o sofrimento e diminuir as perdas. Por fim, a recuperação é o processo de restabelecimento das condições normais de vida na comunidade afetada, iniciando-se imediatamente após a finalização da fase de emergência, ou gestão dos desastres. Contém duas áreas: a reabilitação e a reconstrução (Lapolli, 2013).

Trazendo a discussão para o gerenciamento de riscos de acidentes de trabalho, objeto deste estudo, Bergamini (1997) ressalta que a melhoria da segurança, saúde e meio ambiente de trabalho aumenta a produtividade e minimiza o custo do produto final, pois diminui interrupções no processo, absenteísmo e acidentes e/ou doenças ocupacionais. 
A literatura relacionada à gestão dos riscos do trabalho não distingue as fases do: antes, durante e depois dos acidentes. Por isso, buscaram-se em temas similares modelos de processos que contemplassem tal segmentação, visto que o esforço e o tipo de ações são distintos nas diferentes fases do processo.

\subsection{Estudos anteriores}

Piza (2000) e outros autores, como Benite (2004) e Melo et al. (2008), apontam que a prevenção sempre é o melhor caminho frente aos riscos de acidentes de trabalho. Outro fato observado, e já contextualizado, diz respeito à composição dos custos para estimar sua mensuração e impactos. Não há um entendimento único na literatura para nomear/classificar os custos nem como ocorre essa composição.

Para Benite (2004), os custos dispendidos com os acidentes, mais especificamente os custos da não segurança, devem-se a um tratamento inadequado da saúde e segurança do trabalho (SST). $\mathrm{O}$ autor analisou a implantação de um sistema de gestão da segurança para empresas construtoras por meio de um estudo de caso em uma empresa da construção civil, por ser esse um dos setores que mais apresentavam acidentes à época. Seus resultados mostraram que havia a crença na empresa de que os acidentes ocorriam por culpa dos trabalhadores, e não porque o ambiente era inadequado. Perceberam ainda que as construtoras atuavam de forma reativa em relações ao que recomendava a legislação, concluindo assim que, mais importante que implantar um sistema de gestão, era necessário criar ali uma cultura de prevenção na empresa.

Nessa mesma linha, Franz (2006) buscou comparar os custos dos acidentes ocorridos e os custos efetuados para prevenir possíveis acidentes, analisando uma empresa do setor da construção civil em Florianópolis. Os resultados apontaram maior custo com relação aos investimentos para prevenir possíveis acidentes do que com relação àqueles que efetivamente ocorreram, porém a autora sustenta que o investimento na prevenção traz retorno à empresa na medida em que "diminui o afastamento dos trabalhadores dos seus postos de trabalho e traz a sensação aos funcionários de que o empresário se preocupa com suas vidas" (Franz, 2006, p. 45). Afirma ainda que, sem os custos (investimentos nesse caso) em segurança, os riscos de acidentes seriam maiores, até por possível estresse e desmotivação, e que os valores para reparar esses acidentes seriam elevados, como, por exemplo, custos que viriam de processos trabalhistas. Conclui assim que investir em segurança ao longo do tempo traz retorno.

Lopes et al. (2010) estudaram custos similares, mas ao invés de custos de segurança e não segurança usaram os termos segurado e não segurado. Os custos segurados são relacionados à folha dos funcionários, ao fator previdenciário, etc., e os custos não segurados seriam os demais relacionados ao acidente. Os autores procuraram analisar e compreender a relação entre esses custos a partir da análise de acidentes ocorridos em 2007 em duas empresas de autopeças do ABC paulista. A pesquisa apontou despreocupação das empresas em atentar-se e contabilizar os custos não segurados, que no caso referiam-se principalmente aos relacionados à mão de obra. As relações encontradas indicam menor preocupação com acidentes, já que o salário pago aos empregados também é menor. Nesse setor usa-se mão de obra de baixo custo e, logo, têm-se baixo custo não segurado, apesar da alta gravidade dos acidentes. Em resumo, afirmam os autores que são mais vidas em riscos e menor investimento em qualificação e preparação.

Bonfante et al. (2017) conduziram estudo da gestão dos riscos de acidente de trabalho nas maiores empresas industriais de um pequeno município catarinense. Os resultados do estudo mostraram falhas no cumprimento da legislação, nas políticas da empresa para com o tema e, consequentemente, significativo número de acidentes. Embora não fosse o objetivo do tema, notou-se nesse estudo que alguns empresários reclamaram da situação custo-benefício de realizar uma gestão de riscos sobre acidentes de trabalho.

Devido à falta de uma congruência maior entre os termos apresentados no universo dos custos e de estudos que integrem gestão de custos e gestão de riscos - e procurando ainda entender de que forma se onera mais - o estudo buscou um modelo que se adequasse ao objetivo então proposto, o modelo apresentado pela Proteção e Defesa Civil (Figura 1).Também devido aos vários 
termos adotados, como "custo", "despesa" e "desembolso", neste estudo será adotada a nomenclatura "custos" para discriminar valores despendidos com a SST.

\section{METODOLOGIA}

Diante da relevância de permitir aos gestores simular custos nas diversas fases do processo de gerenciamento de riscos de acidentes de trabalho, este estudo propõe uma ferramenta de simulação para custos do processo de prevenção, mitigação, preparação, resposta e recuperação em gestão de riscos do trabalho. Trata-se de uma pesquisa descritiva com abordagem qualitativa, realizada como estudo de caso, mas cujos resultados podem ser generalizados, mediante adequação do instrumento gerado.

Sugere-se que inicialmente se reconheça uma nova estrutura e classificação dos custos. A literatura propõe classificar em custos diretos versus custos indiretos, ou em custos segurados versus custos não segurados, ou ainda em custos da prevenção versus custos de acidente. Considerando os distintos momentos em que podem e devem incidir custos, para evitar o acidente, ou minimizar seus efeitos, ou ainda preparar a equipe para a resposta e recuperação quando da ocorrência do acidente, propõem-se uma nova classificação, para o processo de gerenciamento de riscos de acidentes de trabalho mais ampla. A Figura 2 representa a nova classificação proposta por esta pesquisa, considerando que os custos podem ocorrer em três momentos distintos em relação ao acidente: antes; durante e depois.

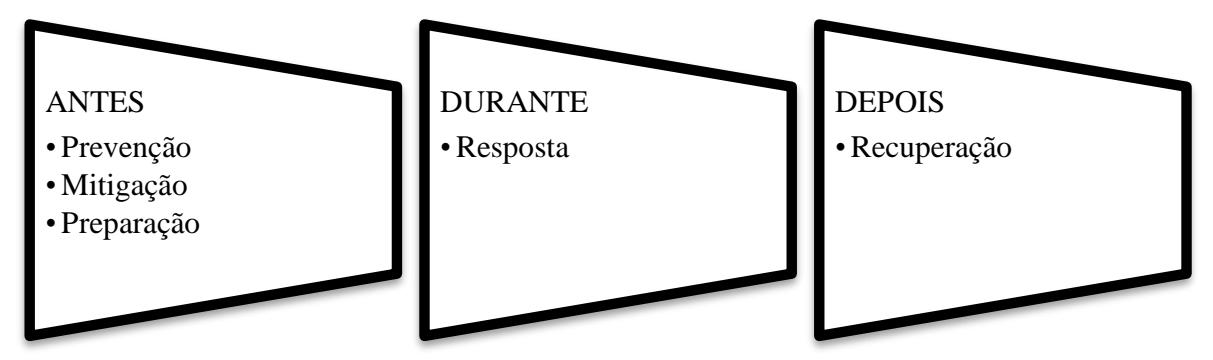

Figura 2. Classificação de custos para gestão de riscos e acidentes de trabalho Fonte: elaborada pelos autores (2018).

Elaborou-se um instrumento de simulação que permite comparar a atual classificação de custos na gestão de riscos em acidentes de trabalho com a nova estrutura proposta, cujos elementos de custos foram obtidos de diversos estudos, unificados.

Elaborado o instrumento de simulação, buscou-se sua validação, por meio de uma entrevista com o proprietário de uma empresa do ramo da construção civil. O estudo de caso permitiu o levantamento de dados relacionados com o gerenciamento de riscos de acidentes de trabalho no ano de 2016, bem como dos custos com os acidentes ocorridos na mesma empresa. A coleta de dados ocorreu no mês de abril de 2017 mediante duas entrevistas semiestruturadas e análise de documentos, como PPRA, PCMSO e CATs.

Foi entrevistado o proprietário da empresa, escolhida intencionalmente. A entrevista seguiu o roteiro de elementos listados no instrumento de simulação, que será objeto de discussão na próxima seção. A partir dos elementos de custos apresentados por ABNT (2001); Benite (2004); Franz (2006); e Lopes et al. (2010), buscou-se a unificação em um padrão convergente, inclusive respeitando sua classificação, separados por custos diretos e custos indiretos, conforme Tabela 2. 


\section{Tabela 2}

Elementos de custos diretos e indiretos na gestão de riscos de acidentes de trabalho

\begin{tabular}{|c|c|}
\hline Sigla & Custos Diretos \\
\hline $\mathrm{Da}$ & Manutenção de equipes de segurança do trabalho \\
\hline $\mathrm{Db}$ & Tempo de desenvolvimento de projetos e instalações de proteção coletiva \\
\hline Dc & Tempo dos trabalhadores utilizados durante as atividades de treinamentos \\
\hline Dd & Manutenção da infraestrutura \\
\hline De & Custos com exames médicos/PCMSO \\
\hline Df & Aquisição de EPIs \\
\hline $\mathrm{Dg}$ & Placas de identificação e orientação aos trabalhadores \\
\hline $\mathrm{Dh}$ & Programa PPRA \\
\hline $\mathrm{Di}$ & Custo relacionado ao seguro SAT \\
\hline Sigla & Custos Indiretos \\
\hline Ia & Despesas jurídicas \\
\hline $\mathrm{Ib}$ & Tempo de recrutamento e gasto com treinamento para novo colaborador \\
\hline Ic & Custo do atendimento médico, medicamentos e reabilitação ao trabalho \\
\hline Id & Pagamentos dos 15 dias de afastamento e de possíveis indenizações \\
\hline $\mathrm{Ie}$ & Perdas e custos de danos de máquinas e equipamentos \\
\hline If & Perda de tempo de trabalho do acidentado e dos companheiros de trabalho \\
\hline $\operatorname{Ig}$ & Perda de motivação e queda na produtividade \\
\hline Ih & $\begin{array}{l}\text { Possível aumento de custo para o empregador com relação à previdência social e outras instituições } \\
\text { que asseguram benefícios aos trabalhadores }\end{array}$ \\
\hline Ii & $\begin{array}{l}\text { Custo adicional devido à interrupção da produção, gerado por dificuldade em cumprir as atividades } \\
\text { no tempo requerido, multas por atraso, perda de bonificações por atendimento de prazo, pagamento } \\
\text { de horas extras, entre outros }\end{array}$ \\
\hline $\mathrm{Ij}$ & $\begin{array}{l}\text { Custos de acidentes subsequentes, em consequência da agitação ou fraqueza moral - estado emocional } \\
\text { - dos demais empregados devido à ocorrência de acidente inicial }\end{array}$ \\
\hline $\mathrm{Ik}$ & $\begin{array}{l}\text { Custo ao empregador do pagamento integral do salário ao acidentado quando de seu retorno, mesmo } \\
\text { que o serviço realizado por este empregado - que ainda não está plenamente recuperado - tenha por } \\
\text { algum tempo valor inferior ao seu valor normal }\end{array}$ \\
\hline Il & $\begin{array}{l}\text { Custos indiretos por acidentado, como gastos com iluminação, aluguel e outros itens que continuam } \\
\text { para empresa, mesmo enquanto o acidentado ainda está ausente e não produz }\end{array}$ \\
\hline
\end{tabular}

Fonte: elaborada pelos autores (2018).

A partir dos elementos constantes na Tabela 2, elaborou-se o instrumento em planilha do $M S$-Excel, que pode ser visualizado na seção seguinte, em que ocorre sua validação em um caso real.

\section{VALIDAÇÃO DO INSTRUMENTO}

Apresenta-se nesta seção o estudo de caso abordado na pesquisa empírica. Trata-se de uma empresa que atua na construção civil no Alto Vale do Itajaí, interior do estado de Santa Catarina. No intuito de resguardar informações sigilosas sobre a empresa estudada, utiliza-se o pseudônimo "Empresa ABC".

A Empresa ABC, que possuía 86 empregados registrados, em média, no ano de 2016, executa diferentes obras, a exemplo de galpões, calçadas, calçamento de ruas, entre outras, e atende a legislação de segurança no trabalho.

Em entrevista, o proprietário revelou os custos resultantes da gestão de riscos de acidentes de trabalho, bem como os dos próprios acidentes ocorridos. Os elementos de custos foram definidos com base em estudos anteriores, conforme mencionado na seção de metodologia, e constam da Tabela 2. Para validação do instrumento, foram identificados custos com gerenciamento de riscos de acidentes de trabalho da Empresa $\mathrm{ABC}$, diretos ou indiretos. Os dados encontram-se na Tabela 3. 


\section{Tabela 3}

Custos com a gestão de riscos de acidentes de trabalho da Empresa ABC, 2016

\begin{tabular}{|c|c|c|c|c|c|c|}
\hline \multirow{3}{*}{$\begin{array}{l}\text { Elemento } \\
\text { de custo }\end{array}$} & \multirow{3}{*}{$\begin{array}{c}\text { Custos Anuais } \\
\text { em R\$ }\end{array}$} & \multicolumn{5}{|c|}{ Classificação proposta no modelo } \\
\hline & & \multicolumn{3}{|c|}{ Antes } & \multirow{2}{*}{$\begin{array}{l}\text { Durante } \\
\text { Resposta }\end{array}$} & \multirow{2}{*}{$\frac{\text { Depois }}{\text { Recuperação }}$} \\
\hline & & Prevenção & Mitigação & Preparação & & \\
\hline $\mathrm{Da}$ & $1.880,00$ & 376,00 & 376,00 & 376,00 & 376,00 & 376,00 \\
\hline $\mathrm{Db}$ & $3.880,00$ & $1.940,00$ & $1.940,00$ & & & \\
\hline Dc & $1.500,00$ & 750,00 & 750,00 & 750,00 & & \\
\hline $\mathrm{Dd}$ & $2.500,00$ & $2.500,00$ & & & & \\
\hline De & $4.500,00$ & $4.500,00$ & & & & \\
\hline Df & $3.120,00$ & $2.496,00$ & 624,00 & & & \\
\hline $\mathrm{Dg}$ & $1.240,00$ & $1.240,00$ & & & & \\
\hline $\mathrm{Dh}$ & $3.850,00$ & $1.283,33$ & $1.283,33$ & $1.283,33$ & & \\
\hline Di & $41.000,00$ & $41.000,00$ & & & & \\
\hline $\begin{array}{l}\text { Sub-total } \\
\text { Diretos }\end{array}$ & $63.470,00$ & $56.085,33$ & $4.973,33$ & $2.409,33$ & 376,00 & 376,00 \\
\hline Ia & - & & & & & \\
\hline $\mathrm{Ib}$ & $4.300,00$ & & & & & $4.300,00$ \\
\hline Ic & $1.125,00$ & & & & 787,50 & 337,50 \\
\hline Id & $11.250,00$ & & & & & $11.250,00$ \\
\hline Ie & $17.000,00$ & & & & & $17.000,00$ \\
\hline If & $6.100,00$ & & & & $6.100,00$ & \\
\hline $\operatorname{Ig}$ & $8.000,00$ & & & & & $8.000,00$ \\
\hline Ih & - & & & & & - \\
\hline $\mathrm{Ii}$ & $4.800,00$ & & & & & $4.800,00$ \\
\hline $\mathrm{Ij}$ & - & & & & & - \\
\hline $\mathrm{Ik}$ & $4.200,00$ & & & & & $4.200,00$ \\
\hline Il & - & & & & & - \\
\hline $\begin{array}{l}\text { Sub-total } \\
\text { Indiretos }\end{array}$ & $56.775,00$ & - & - & - & $6.887,50$ & 49.887,50 \\
\hline Total & $120.245,00$ & $56.085,33$ & $4.973,33$ & $2.409,33$ & $7.263,50$ & $50.263,50$ \\
\hline
\end{tabular}

Fonte: dados da pesquisa (2016).

Alguns custos indiretos não puderam ser apurados pela empresa, todavia, segundo o proprietário, não são significativos. Pela classificação tradicional dos custos em diretos e indiretos, nota-se que a empresa gasta mais na prevenção de acidentes que nos custos gerados pelos próprios acidentes. Ferreira et al. (2012) afirma que acidentes de trabalho geram custos e, por isso, a melhor maneira de minimizá-los nas empresas ainda é investir na prevenção, objetivos dos profissionais de segurança do trabalho.

Buscou-se classificar os custos diretos e indiretos em custos da prevenção, mitigação, preparação, resposta e recuperação, cujo processo é amplamente discutido na gestão de riscos e desastres. Mais uma vez, os dados revelam que a empresa praticamente equilibrou seus custos, considerando os momentos antes (prevenção, mitigação e preparação) e após a ocorrência do acidente (resposta e recuperação). Embora possa significar equilíbrio, é importante destacar que investimentos realizados antes dos acidentes preservam a vida e o patrimônio, ao mesmo tempo que a segurança no trabalho gera um ambiente favorável à maior produtividade. 
A Figura 3 demonstra o custômetro de toda a operação de gestão de risco de acidente de trabalho.

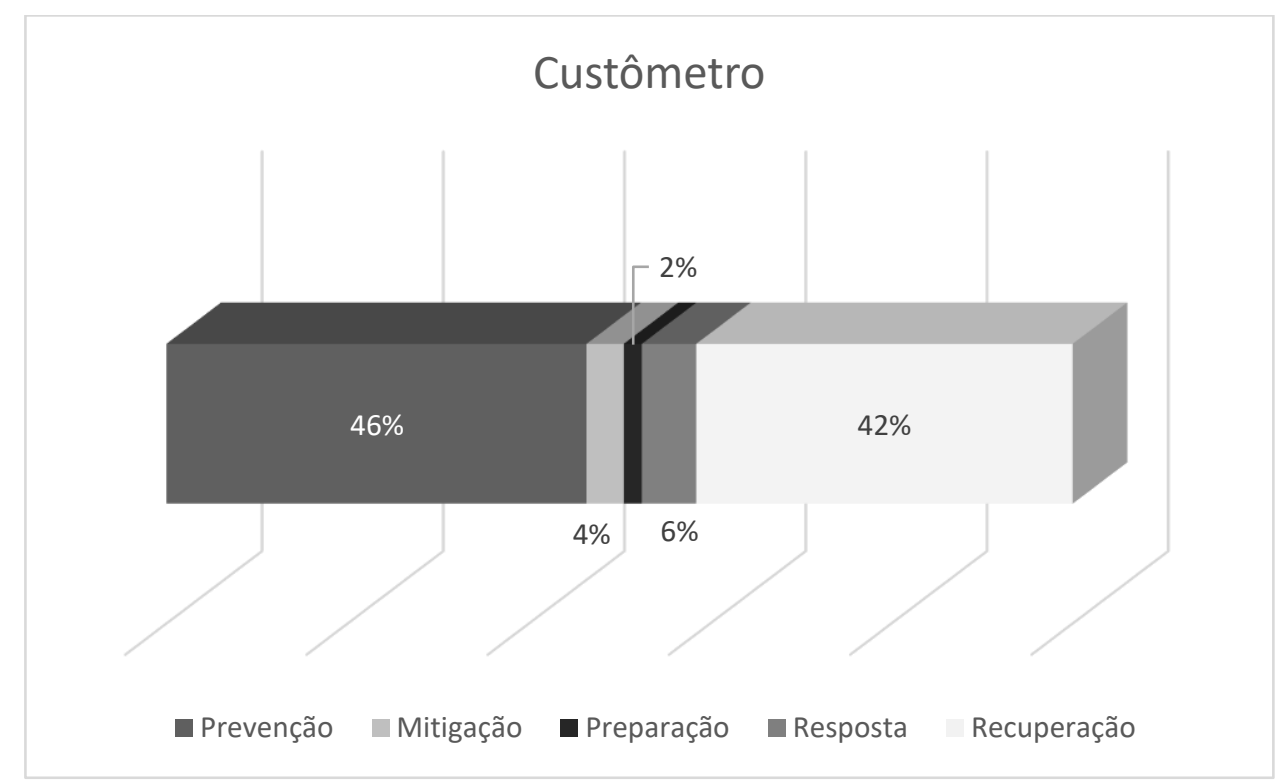

Figura 3. Custômetro

Nota. Representa o percentual de cada classificação de custos em relação ao custo total da gestão de riscos de acidente de trabalho da Empresa ABC.

Fonte: dados da pesquisa (2016).

Pelo estudo de caso constatou-se que os maiores acidentes envolveram colisão de veículos da própria empresa (apenas danos materiais). Além disso, ocorreu um acidente inusitado em que um empregado (no solo) arremessou uma ferramenta de trabalho em outro empregado (no telhado da obra), momento em que este salta da obra para perseguir o agressor, sofrendo uma fratura exposta na perna direita. A obra ficou paralisada no dia (a partir das 14:30), a recuperação plena do empregado levou seis meses. Um terceiro acidente com maiores proporções envolveu uma serra elétrica (disco de corte) que resultou na amputação de um dedo na mão esquerda de um empregado, ficando este afastado das atividades por 120 dias, comprometendo parcialmente as atividades no retorno ao trabalho.

Segundo o proprietário, o ano de 2016 foi um divisor de águas para a empresa, pois começaram a colher os resultados do investimento em prevenção. Nesse período houve diminuição dos acidentes e, consequentemente, de custos em relação a anos anteriores.

Em relação ao instrumento apresentado, nota-se que a classificação de custos prevista permite melhor visualização dos investimentos em cada fase do processo de gerenciamento de riscos de acidentes de trabalho. Isso ocorre porque os gestores poderão visualizar os custos que efetivamente vêm ao encontro da prevenção dos acidentes e, quando não são passíveis de prevenção, a minimização dos efeitos por meio dos custos de mitigação, além da preparação da equipe para que a resposta e a recuperação possam ser otimizadas quando os acidentes ocorrerem.

\section{CONCLUSÃO}

Esta pesquisa cumpriu o objetivo de desenvolver uma ferramenta de simulação de custos para a gestão de riscos de acidentes de trabalho. Os elementos de custos foram definidos com base em pesquisas anteriores e a metodologia de gestão foi adaptada. A implementação em um caso real trouxe a validação necessária para dar robustez do instrumento, que pode ser generalizado.

Apesar dos esforços dos órgãos reguladores e das empresas, no cenário brasileiro os acidentes continuam com índices alarmantes, gerando gastos às empresas e à economia como um todo, além da dor e do sofrimento físico dos envolvidos. Na literatura, a prevenção é sempre apontada como o melhor caminho, porém, percebeu-se nessa pesquisa que nem sempre os gestores estão conscientes da importância de fazer um planejamento dos riscos laborais. Ademais, quando 
resolvem fazê-lo, não têm certeza do modo eficiente para isso, ou seja, em quê e quanto alocar de recursos para fazer um plano de prevenção.

Os diversos estudos realizados costumam se concentrar em dividir os custos em diretos ou indiretos, de segurança e não segurança, de prevenção e do acidente, não encontrando uma padronização na nomenclatura. Nesse sentido, o objetivo proposto permite ao gestor mensurar os custos em cada fase do processo de gerenciamento de riscos de acidentes de trabalho, trazendo uma visão mais ampla do processo de gestão.

De acordo com o modelo inédito apresentado nesta pesquisa, poderão ser mensurados os custos da gestão de riscos de acidente de trabalhos nas mais diversas empresas, já que ele permite generalização. A distribuição dos elementos de custos pode ser adaptada ao ramo de atividade da empresa, porém a proposta é classificá-los em: antes (prevenção, mitigação e preparação), durante (resposta) e depois (recuperação) do acidente de trabalho.

Desse modo é imperativo destacar a importância do instrumento de simulação para que gestores de riscos conheçam seus custos relacionados e a partir destes desenvolvam estratégias que possam proteger a vida e o patrimônio daqueles que compõem as organizações, sugerindo futuras pesquisas nessa área. Com a ampliação das pesquisas utilizando esse novo modelo, no futuro, poderá ser possível comparar os resultados dos custômetros de empresas com características similares.

\section{REFERÊNCIAS}

Araújo, R. P., Santos, N., \& Mafra, W. J. (2006). Gestão da saúde e segurança do trabalho. Anais do Simpósio de Excelência em Gestão e Tecnologia, Rio de Janeiro, RJ, Brasil, 3.

Associação Brasileira de Normas Técnicas. (2001). Cadastro de acidente do trabalho: procedimento e classificação. NBR 14280/2001. Rio de Janeiro: ABNT.

Benite, A. G. (2004). Sistema de gestão da segurança e saúde no trabalho para empresas construtoras. 236 f. Dissertação de Mestrado em Engenharia, Universidade de São Paulo, SP, Brasil.

Bergamini, C. W. (1997). Motivação nas organizações. São Paulo: Atlas.

Bonfante, E. A., Eyerkauser, M. L., \& Dallabona, L. F. (2017). Gestão dos riscos de conformidade em segurança do trabalho. Anais do Congresso Brasileiro de Redução de Riscos e Desastres. Rio de Janeiro, RJ, Brasil, 2.

Centro Universitário de Estudos e Pesquisas Sobre Desastres da Universidade Federal de Santa Catarina. (2014). Gestão de recursos federais de Defesa Civil (2a ed.). Florianópolis: CEPED/UFSC.

Ching, H. I. (2011). Contribuição das boas práticas do mercado para a eficiência na gestão do risco corporativo. Revista Brasileira de Estratégia, 4(3), 257-273.

Committee of Sponsoring Organizations of the Treadway Commission. (2007). Gerenciamento de riscos corporativos - estrutura integrada.1-141. Recuperado em 18 dezembro, 2018, de: http://www.coso.org/documents/COSO_ERM_ExecutiveSummary_Portuguese.pdf

Dalvesco, D. G., Fernandes, F. C., \& Roncon, A. (2014). Controles de gestão atrelados ao gerenciamento de risco: uma análise das produções científicas brasileiras sob a perspectiva de redes sociais. Revista hispana para el análisis de redes sociales, 25(2), 163-185.

Eyerkaufer, M. E. (2017). Modelo de referência organizacional estratégico para coordenação local da gestão dos riscos e desastres. 178 p. Tese de doutorado, Universidade Federal de Santa Catarina, Florianópolis, SC, Brasil. 
Fabre, V. V. \& Eyerkaufer, M. E. (2018). Disclosure voluntário na governança de gestão de riscos e desastres: um instrumento de pesquisa. Revista Livre de Sustentabilidade $e$ Empreendedorismo, 3(2), 149-169.

Ferreira, M. M., Souza, C. E. S., Ribeiro, C. A., Galdino, D. B., \& Ricci, G. L. (2012). Avaliação sobre a prevenção de riscos na atividade de trabalho em prensas. Iberoamerican Journal of Industrial Engeneering, 4(8), 48-68.

Franz, L. (2006). Estudo comparativo dos custos de prevenção e os custos dos acidentes de trabalho na construção civil. 60 f. Monografia de Graduação em Ciências Contábeis, Universidade Federal de Santa Catarina, Florianópolis, SC, Brasil.

Hämäläinen, P., Saarela, K. L., \& Takala, J. (2009). Global trend according to estimated number of occupation al accidents and fatal work related diseases at region and country level. Journal of Safety Research, 40(2), 125-139. doi: 10.1016/j.jsr.2008.12.010.

Iwamoto, H. H., Camargo, F. C., Tavares, L. C., \& Miranzi, S. S. C. (2011). Acidentes de trabalho fatais e a qualidade das informações de seus registros em Uberaba, em Minas Gerais e no Brasil, 1997 a 2006. Rev. Brasileira de Saúde Ocupacional, 36(124), 208-215. doi: 10.1590/S0303-79572011000200004.

Lapolli, A. V. (2013). O plano diretor e o plano de gerenciamento de enchentes do município de Rio do Sul - SC: a construção de um território seguro? 208f. Dissertação de Mestrado em Planejamento Territorial e Desenvolvimento Socioambiental, Universidade do Estado de Santa Catarina, Florianópolis, SC, Brasil.

Lima, F. (2003). Os Custos dos Acidentes de Trabalho nas Empresas de Construção. Instituto Superior Técnico, Universidade Técnica de Lisboa e CEGIST. Recuperado em 18 dezembro, 2018, de: https://fenix.tecnico.ulisboa.pt/downloadFile/1970943312291338/2003_Acidentes-deTrabalho_WP_CEG-IST_

Liu, H., Hwang, S., \& Liu, T. (2009). Economic assessment of human errors in manufacturing environment. Safety Science, 47, 170-182. doi: 10.1016/j.ssci.2008.04.006

Lopes, J, N, P., Queiroz, R. P., \& Leonardi, F. (2010). A relação entre os custos segurado e custo não segurado dos acidentes de trabalho. Anais do Encontro Nacional de Engenharia de Produção, São Carlos, SP, Brasil, 30.

Maia, A. L. S. (2015). Acidentes de trabalho no Brasil em 2013: comparação entre dados selecionados da Pesquisa Nacional de Saúde do IBGE (PNS) e do Anuário Estatístico da Previdência Social (AEPS) do Ministério da Previdência Social. Recuperado em 17 dezembro, 2018, de www.fundacentro.gov.br/arquivos/projetos/estatistica/boletins/boletimfundacentro1vfinal.p df

Martins, E. (2010). Contabilidade de Custos. São Paulo: Atlas.

Melo, M. B. F. V., Castro, I. S., \& Regis, T. K. O. (2008). Segurança e saúde na atividade laboral: uma contribuição para a qualidade de vida da comunidade - relato de uma experiência. Anais do Encontro Nacional de Engenharia de Produção, Rio de Janeiro, RJ, Brasil, 17.

Ministério da Saúde. (2014). Inquérito sobre Atendimentos por Violências e Acidentes em Serviços Sentinela de Urgência e Emergência do Sistema de Vigilância de Violências e Acidentes (VIVA)-Capitais, Distrito Federal e municípios selecionados. Brasília, DF.

Office of U.S. Foreign Disaster Assistance. (2011). Bases Administrativas para gestão de riscos - BAGER: Material de Referência. (A. V. Lapolli \& A. F. Pinheiro, Tad. e adapt ). Costa Rica: USAID/OFDA/LAC. 
Pastore, J. (2011). O custo dos acidentes e doenças do trabalho no Brasil. Recuperado em 17 dezembro, 2018, de http://www.josepastore.com.br/artigos/rt/rt_320.htm

Parente, P. H. N., Luca, M. M. M., \& Vasconcelos, A. C. (2015). Teoria contingencial e intangibilidade: um estudo nas empresas listadas na BM\&F Bovespa. Revista Enfoque Contábil, Maringá, 34(3), 21-40. doi: 10.4025/enfoque.v34i3.29568.

Piza, F. T. (2000). Prevenção é sinônimo de lucro. São Paulo: Revista CIPA.

Portal do Brasil. (2014). Ministério divulga análises de acidentes de trabalho. Recuperado em 17 dezembro, 2018, de: http://www.brasil.gov.br/economia-e-emprego/2014/12/ministeriodivulga-analises-de-acidentes-de-trabalho

Project Management Body of Knowledge.(2012). A Guide to the Project Management Body of Knowledge, PMI.

Ramos, D. G. G., Arezes, P. M., \& Afonso, P. (2014). Economic analysis of occupation al risk prevention: A case study in a textile company. In R. D. J. M. Steenbergen, P. H. A. J. M. van Gelder, S. Miraglia, A. C. W. M. Vrouwenvelde (Eds.). Safety, Reliability and Risk Analysis: Beyond the Horizon (Chap. 5, pp. 1473-1478). London: Taylor \& Francis Group.

Revista Proteção (2016). Anuário brasileiro de proteção 2015. Recuperado em 17 dezembro, 2018, de http://www.protecao.com.br/materias/A5jy.

Santana, V. S., Araújo, J. B., Albuquerque, P. O., \& Barbosa, A. B. (2006). Acidentes de trabalho: custos previdenciários e dias de trabalho perdidos. Revista Saúde Pública, 40(6), 1004-1012. doi: 10.1590/S0034-89102006000700007.

Silva, F. P. \& Mendonça, T. M. (2012). Segurança do Trabalho: um estudo em uma empresa da construção civil na cidade de Maceió. Anais do Simpósio de Excelência em Gestão e Tecnologia. Maceió, AL, Brasil, 9.

Soares, J. F. S. (2012). Incidência cumulativa anual de acidentes de trabalho não fatais, estimativas nacionais para o Brasil. 108f. Tese de Doutorado em Saúde Pública, Universidade Federal da Bahia, Salvador, BA, Brasil.

Takala, J., Hämäläinen, P., Saarela, K.L., Yun, L.Y., Manickam, K., Jin, T.W., Heng, P. Tjong, C., Kheng, L. G., Lim, S., \& Lin, G. S. (2014). Global estimates of the burden of in jury and illness at work in 2012. Journal of Occupation al and Environmental Hygiene, 11(5), p. 236337. doi: $10.1080 / 15459624.2013 .86313$

Tavares, F., Pacheco, L., \& Pires, M. (2016). Gestão do risco nas PME de Excelência portuguesas. Tourism e Management Studies, 12(2),135-144. doi: 0.18089/tms.2016.12215

United Nations International Strategy for Disaster Reduction. (2009). Terminología sobre Reducción del Riesgo de Desastres. Recuperado em 18 dezembro, 2018, de: www.unisdr.org/files/7817_UNISDRTermonologySpanish.pdf

Vianna, J. S. \& Santos, N. T. (1976). Manual de prevenção de acidentes. Rio de Janeiro: Freitas Bastos. 